\title{
Numerical Study of the Air Ingress Accident of the HTR-PM and Possible Mitigation Measures
}

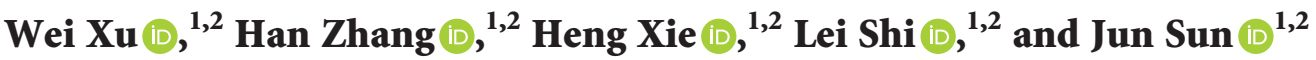 \\ ${ }^{1}$ Institute of Nuclear and New Energy Technology, Tsinghua University, Beijing 100084, China \\ ${ }^{2}$ Key Laboratory of Advanced Reactor Engineering and Safety, Ministry of Education, Beijing 100084, China \\ Correspondence should be addressed to Jun Sun; sunjun@mail.tsinghua.edu.cn
}

Received 2 June 2020; Revised 13 October 2020; Accepted 27 October 2020; Published 11 November 2020

Academic Editor: Arkady Serikov

Copyright $\odot 2020$ Wei Xu et al. This is an open access article distributed under the Creative Commons Attribution License, which permits unrestricted use, distribution, and reproduction in any medium, provided the original work is properly cited.

\begin{abstract}
The double-ended guillotine break (DEGB) of the horizontal coaxial gas duct of a high-temperature gas-cooled reactor is an extremely hypothetical accident, which could cause the air to enter into the primary circuit and react with graphite in the reactor core. The performance of the HTR-PM plant under this extremely hypothetical accident has been studied by the system code TINTE in this work. The results show that the maximum fuel temperature will not reach the temperature design limitation, and the graphite oxidation will not cause unacceptable consequences even under some conservative assumptions. Moreover, nitrogen and helium injected from the fuel charging tube were studied as the possible mitigation measures to further alleviate the consequences of this air ingress accident. The preliminary results show that only the flow rate of nitrogen injected reaches a certain value, which can effectively alleviate the consequences, while for helium injection, both high and small flow rate can prevent or cut off the natural circulation and alleviate the consequences. The reason is that helium is much lighter than nitrogen, and the density difference between the coolant channel and the reactor core is small when helium is injected. Considering the injection velocity, the total usage amount, and the start time of gas injection, helium injected with a small flow rate is suggested.
\end{abstract}

\section{Introduction}

The high-temperature gas-cooled reactor has been a candidate of the Generation IV nuclear energy system technology due to its advanced inherent safety [1]. As discussed by Lohnert and Reutler [2], the fuel temperature of the modular High-Temperature gas-cooled Reactor (HTR) will never exceed the design limitation even in the case of failure of all active cooling systems and complete loss of forced cooling.

At the end of 2012, the 200 MWe High-Temperature gascooled Reactor Pebble-bed Module (HTR-PM) which is designed by the Institute of Nuclear and New Energy Technology (INET) of Tsinghua University was started to be constructed in Rongcheng, Shandong Province, China. HTR-PM is a commercial demonstration power plant and will connect to the national grid power in the future. Figure 1 provides the cross section of the primary circuit of the HTRPM [1]. As shown in Figure 1, the primary circuit pressure boundary of the HTR-PM is composed of the reactor pressure vessel, the steam generator pressure vessel, and the horizontal coaxial gas duct vessel. The break or leak of the primary circuit pressure boundary would cause air ingress accident.

There are two kinds of scenarios which are being researched extensively by researchers: one is the simultaneous rupture of both upper and lower pipes connected to the primary loop, which could cause air ingress due to the chimney effect [3]; the other is the double-ended guillotine break (DEGB) of the horizontal coaxial gas duct, which could also result in air ingress into the primary circuit. These two kinds of air ingress accident are both regarded as Beyond Design Basis Accident (BDBA) of the HTR-PM.

The air may react with graphite in the reactor when the air ingress accident occurred because there are a lot of graphite materials in the reactor such as the matrix graphite of spherical fuel element and graphite reflector. The oxidation of the spherical fuel elements may impact the 


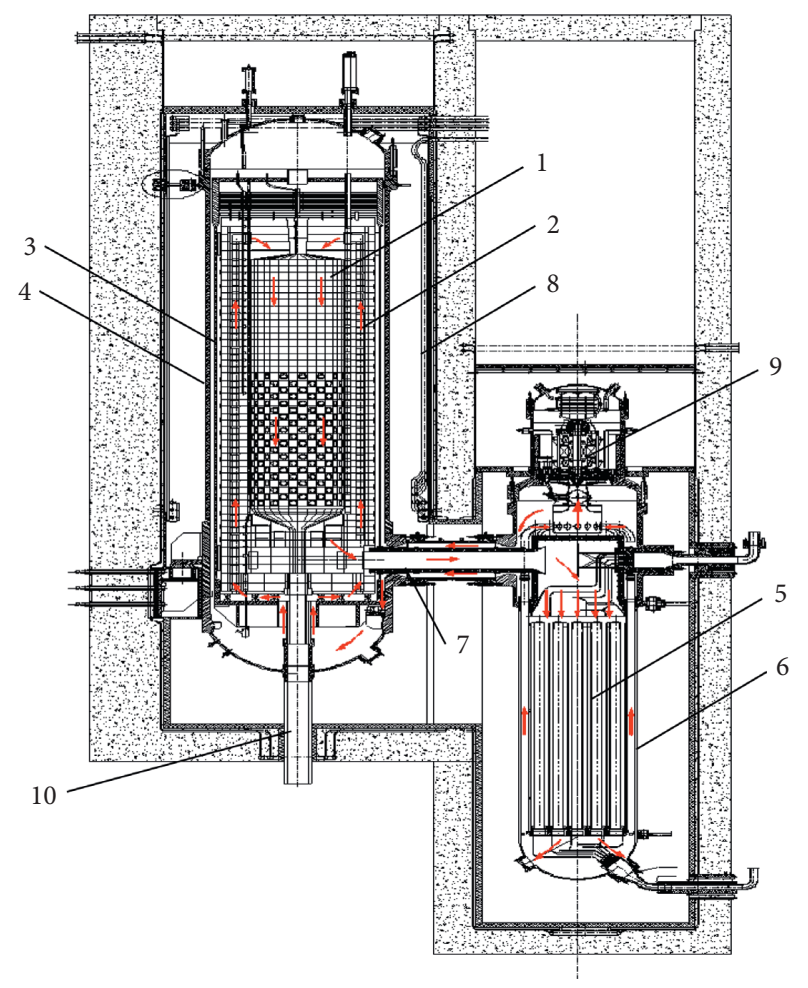

Figure 1: Cross section of the primary circuit of the HTR-PM [1]. (1) Reactor core; (2) side reflector and carbon thermal shield; (3) core barrel; (4) reactor pressure vessel; (5) steam generator; (6) steam generator vessel; (7) coaxial gas duct; (8) water-cooling panel; (9) blower; (10) fuel discharging tube.

retention capacity of the fuel coated particles and may increase the radioactivity released from the fuel elements. At the same time, the oxidation of the bottom reflector may weaken the structural strength and damage the integrity of the graphite structure.

Juelich Research Center has studied the air ingress accident of HTRs from the 1970s and found that the consequences of double-ended guillotine break (DEGB) of coaxial gas duct are more severe than the simultaneous rupture of the upper and lower pipe connected to the primary circuit [4]. JAERI studied a lot about the development of natural circulation after the double-ended guillotine break (DEGB) of the coaxial gas duct and found that the natural convection in the core accelerated the development of natural circulation $[5,6]$. Idaho National Laboratory (INL) also researched the air ingress accident because the air ingress accident was very important based on the Phenomena Identification and Ranking studies [7]. The studies of INL indicated that the air ingress phenomena are different depending on the different locations and different sizes of the pipe break. A fracture model of nuclear graphite was proposed by INL based on the structure tests of the oxidized core bottom structures. A multidimensional code named GAMMA was developed by Korea Atom Energy Research Institute (KAERI) to predict the air ingress accident of hightemperature gas-cooled reactor [8] and the advanced air ingress-related models developed by INL was implemented into the GAMMA code. Shiga discussed the process of air ingress during a depressurization accident of GTHTR300 [9]. The results show that the onset time of natural circulation depends on the location of the horizontal coaxial gas duct and the competition between natural convection and molecular diffusion.

Due to the severe consequences of air ingress accident, INET also has done much research on the air ingress accident. Liu [10] has researched the DEGB of the horizontal coaxial gas duct accident of HTR-10 and suggested injecting $\mathrm{CO}_{2}$ into the core to alleviate these accident consequences. However, the average fuel temperature of the HTR-PM is higher than that of HTR-10, and the $\mathrm{CO}_{2}$ will react with the graphite in the reactor. So $\mathrm{CO}_{2}$ is not a good choice to alleviate the consequences for the HTR-PM. Zheng et al. [11] and Liu [12] have done much work on the DEGB of the horizontal coaxial gas duct accident of the HTR-PM and discussed a lot about the diffusion process of this accident. The results of Zheng et al. [11] showed that it costed dozens of hours to establish a stable natural circulation. Liu [12] figured out that the air concentration in the cavity played an important role in the process of establishing the stable natural circulation and suggested injecting nitrogen with a large flow rate to alleviate the consequences. Xu et al. [13, 14] analyzed the oxidation results of this air ingress accident for the HTR-PM in detail and showed that the bottom reflector material with a higher oxidation rate is a better choice considering this air ingress accident. In this work, the DEGB of horizontal coaxial gas duct accident for the HTR-PM is analyzed by system code TINTE, and the possible mitigation measures are discussed to alleviate the consequences of this air ingress accident.

\section{Air Ingress Accident Sequence and Simulation Model}

The DEGB of the horizontal coaxial gas duct accident process can be divided into three stages according to the existing work $[10,15,16]$ : (1) helium in the reactor quickly bursts into the reactor cavity on account of the large pressure difference between the reactor core and the reactor cavity. (2) After the depressurization, air will slowly diffuse into the reactor and stable natural circulation will finally be established due to the gas density difference between the reactor core and the coolant channel. (3) The graphite in the reactor will be oxidized by air over a long period after the stable natural circulation is built up.

In the first stage, helium quickly pours into the reactor cavity and results in an increase in the pressure of the cavity. The pressure of the primary circuit will decrease rapidly until the pressure of the primary circuit equals the pressure of the reactor cavity. After the pressure equilibrium is reached between the outside (reactor cavity) and the inside (primary circuit), the diffusion process begins.

The gas temperature in the reactor core is higher than the gas temperature in the coolant channel. The stable natural circulation will be established when the driving force caused by gas density difference is sufficient to overcome the resistance along the path. As shown in Figure 2, after having reached a state of stable natural circulation, the air flows into 
the reactor from the inner coaxial gas duct and then flows from the bottom reflector, passing through the core, to the top reflector. Then the air flows from the cold helium plenum, passing through the circular channel, to the cavity between the reactor pressure vessel and the core vessel. Finally, the air flows out from the outer coaxial gas duct to the reactor cavity.

After the stable natural circulation is established, the graphite in the reactor will be oxidized by air over a long period. The onset time and flow rate of stable natural circulation are very important for this third stage. As mentioned above, the severe consequence of air ingress accident is mainly due to the graphite oxidation which may cause the fuel particles to be exposed and the integrity of graphite structure to be damaged.

The system code TINTE is used to simulate the DEGB of horizontal coaxial gas duct accident for the HTR-PM. The TIme-dependent Neutronics and TEmperatures (TINTE) code, developed by the Juelich Research Center in Germany, is a special-designed code to simulate the reactor physics, thermal hydraulics, and chemical dynamic behavior of the primary circuit of HTRs [17]. The TINTE code system deals with the nuclear and thermal transient behavior of the primary circuit of the hightemperature gas reactor, taking into consideration the mutual feedback effects in a two-dimensional axisymmetric geometry. Two-dimensional time-dependent neutronic module, pebble-bed temperature module, fluid dynamics module, chemical corrosion module, and control module are included in the TINTE code. The neutronic calculation and thermal gas calculation are solved separately in the original version TINTE and further developed into the fully implicit coupling methods by INET $[18,19]$. TINTE code has been validated by AVR and some experiments and codes [20-23]. The simulation results of TINTE are well accepted by the HTR research community. In detail, the chemical model in TINTE is validated by the VELUNA corrosion experiments [24]. The component connection under the DEGB of horizontal coaxial gas duct accident is shown in Figure 3, and the TINTE model of the HTR-PM reactor is shown in Figure 4 [1]. There are three kinds of chemical reaction related to the air ingress accident in the TINTE code which are as follows:

$$
\begin{gathered}
2 \mathrm{CO}+\mathrm{O}_{2} \longrightarrow 2 \mathrm{CO}_{2} \quad \Delta H_{1}=-5.64 \times 10^{5} \frac{\mathrm{J}}{\mathrm{mol}} \\
\mathrm{CO}_{2}+\mathrm{C} \rightleftarrows 2 \mathrm{CO} \quad \Delta H_{2}=1.71 \times 10^{5} \frac{\mathrm{J}}{\mathrm{mol}} \\
\mathrm{O}_{2}+\mathrm{C} \longrightarrow \mathrm{CO}_{2} \quad \Delta H_{3}=-3.94 \times 10^{5} \frac{\mathrm{J}}{\mathrm{mol}}
\end{gathered}
$$

In the TINTE code, the reaction rates of reactions (1) (2) are given in the following equations (4) (5). For reaction (3), the reaction rates of the matrix graphite of spherical fuel element and reflector graphite are, respectively, equations (6) and (7).

$$
\begin{aligned}
& \mathrm{Rc}_{1}=1.3 \times 10^{20} \cdot \exp \left(-\frac{1.44 \times 10^{5}}{R \cdot T_{G}}\right) \cdot C(\mathrm{CO}) \cdot \sqrt{C\left(\mathrm{O}_{2}\right)} \cdot \sqrt{C\left(\mathrm{H}_{2} \mathrm{O}\right)}, \\
& \mathrm{Rc}_{2}=2.64 \times 10^{6} \cdot \exp \left(\frac{\left.-\left(3.58 \times 10^{4} / T_{W}\right)\right) \cdot C G R \cdot C_{W}\left(\mathrm{CO}_{2}\right),}{1+8.1 \times 10^{-6} \cdot \exp \left(1.7 \times 10^{4} / T_{W}\right) \cdot \sqrt{C(\mathrm{CO})}+179 \cdot \exp \left(-\left(9.82 \times 10^{3} / T_{W}\right)\right) \cdot C_{W}\left(\mathrm{CO}_{2}\right)}\right. \\
& \mathrm{Rc}_{3}=1667 \cdot \exp \left(-\frac{1.614 \times 10^{4}}{T_{W}}\right) \cdot\left(R \cdot T_{G}\right) \cdot C_{W}\left(\mathrm{O}_{2}\right), \\
& \mathrm{Rc}_{4}=134.376 \cdot \exp \left(-\frac{23815}{T_{W}}\right) \cdot\left(R \cdot T_{G}\right) \cdot \mathrm{CGR} \cdot C_{W}\left(O_{2}\right),
\end{aligned}
$$

where $R c_{1}$ and $R c_{2}$ are the reaction rates of reactions (1) and (2), respectively, $\mathrm{mol} \cdot \mathrm{m}^{-3} \cdot \mathrm{s}^{-1} \cdot \mathrm{Rc}_{3}$ and $\mathrm{Rc}_{4}$ are the oxidation rates of matrix graphite and reflector graphite, respectively. $C(i)$ is the concentration of $i$ in the boundary layer of a solid wall, mol. $\mathrm{m}^{-3} ; C_{W}(i)$ is the concentration of $i$ on the solid wall, mol. $\mathrm{m}^{-3}$, while $i$ means the gas species: $\mathrm{O}_{2}, \mathrm{CO}, \mathrm{CO}_{2}$, and $\mathrm{H}_{2} \mathrm{O}$. CGR is the density of nuclear grade graphite, $\mathrm{mol} \cdot \mathrm{m}^{-3} \cdot T_{G}$ and $T_{W}$ mean the gas temperature and the solid wall temperature, respectively, K. $R$ is the ideal gas constant, which is $8.314 \mathrm{~J} \mathrm{~mol}^{-1} \mathrm{~K}^{-1}$.
To simulate this air ingress accident, the following assumptions have been done:

(1) The initial nuclear power is $100 \%$ rated power, and the keff will be reduced to 0.91 in $200 \mathrm{~s}$

(2) The primary circuit pressure is reduced to $0.1 \mathrm{MPa}$ in $70 \mathrm{~s}$

(3) It is assumed that the amount of air which could be diffused into the reactor is infinite 


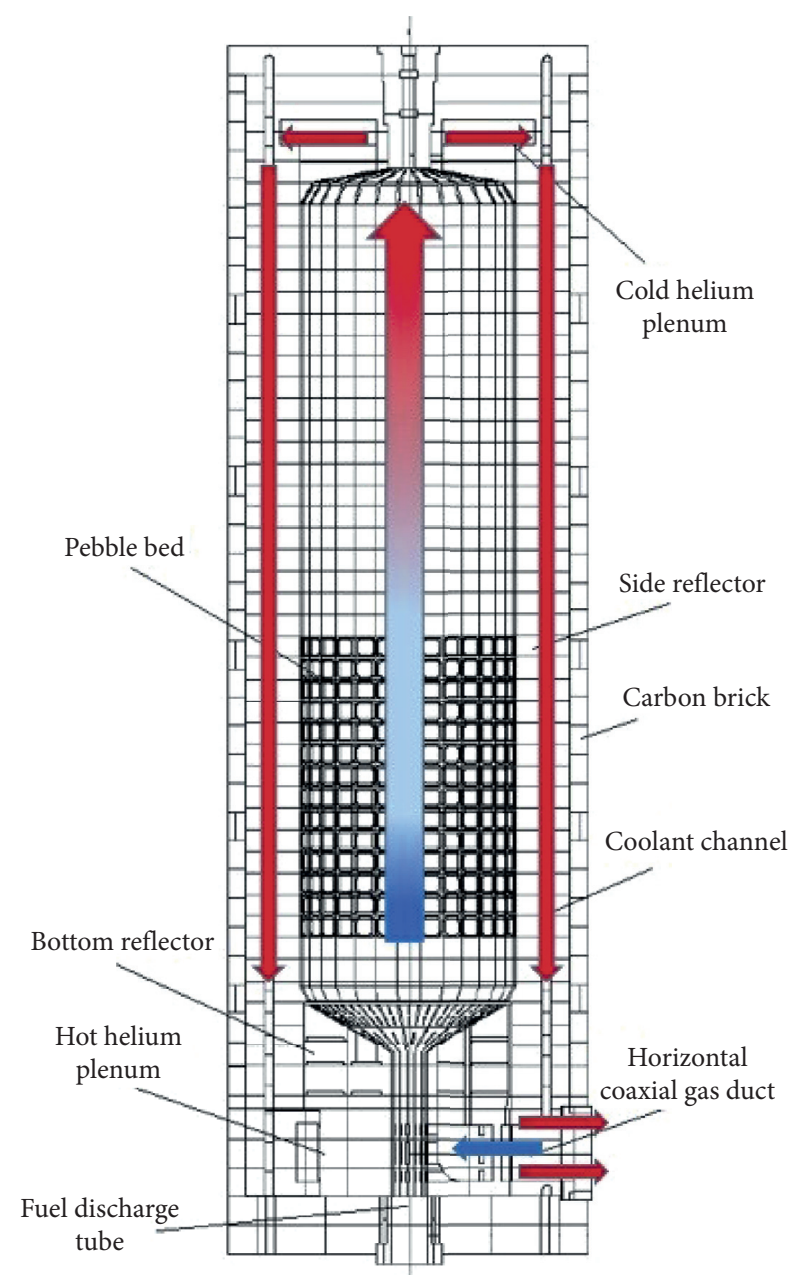

Figure 2: Schematic diagram of gas flow after stable natural circulation is established in the HTR-PM.

(4) The temperature and pressure of air in reactor cavity are, respectively, $35^{\circ} \mathrm{C}$ and $0.1 \mathrm{MPa}$

(5) It is assumed that the product gas will not enter into the reactor again

(6) For the spherical fuel element in the radius direction, it is assumed that the oxidation rate is the same

(7) There are no other protection measurements that will be taken after the reactor shut down; that is to say, the residual heat of the reactor will be carried out in a passive way

Obviously, the assumptions demonstrated above are conservative to simulate the air ingress accident.

\section{Results and Discussion}

3.1. Maximum Fuel Temperature. Three aspects are mainly focused on about the consequences of the air ingress accident: (1) the first aspect is that the maximum fuel temperature during the whole accident exceeds the design limitation. The fission products may be released from the coated fuel particles if the fuel temperature is too high. (2)
The second aspect is that the graphite oxidation affects the integrity of the fuel element and the bottom reflector. (3) The third aspect is that the carbon monoxide produced by the $\mathrm{C} / \mathrm{CO}_{2}$ reaction causes more serious consequences. The following will be discussed about these three aspects in detail.

The fuel temperature design limitation of the HTR-PM is $1620^{\circ} \mathrm{C}$ under accident conditions. Under $1620^{\circ} \mathrm{C}$, the $\mathrm{SiC}$ layer of the coated fuel particles can maintain the integrity and its capability of retaining fission products will not be damaged. In fact, the $\mathrm{SiC}$ layer of the coated fuel particles can maintain integrity even under higher temperature according to the results of the high-temperature irradiation experiment.

Figure 5 shows the maximum fuel temperature variation in time. It presents that the maximum fuel temperature during the air ingress accident is about $1462^{\circ} \mathrm{C}$. Many researchers [25-28] have paid a lot of effort on the uncertainty and sensitivity analysis of the maximum fuel temperature. According to the recent results [28], the effective conductivity of pebble-bed and the decay heat contribute the most uncertainty in the maximum fuel temperature analysis, and the uncertainty of maximum fuel temperature is smaller than $\pm 80^{\circ} \mathrm{C}$ under a two standard deviation $(2 \sigma)$. Therefore, even considering the uncertainty effect, the maximum fuel temperature is $1542^{\circ} \mathrm{C}$ which still has a margin of the temperature design limitation.

3.2. Graphite Oxidation. As mentioned above, the onset time of stable natural circulation is very important for graphite oxidation. The oxygen concentration is relatively small in the reactor before the stable natural circulation is established. So the graphite oxidation is very small and the consequences can be ignored. As shown in Figure 6, stable natural circulation is established at about $73 \mathrm{~h}$. The oxygen concentration at the bottom of the reactor increased obviously after the stable natural circulation is established. Therefore, the graphite oxidation increased significantly after $73 \mathrm{~h}$. The total amount of graphite oxidation in the reactor is about $2231 \mathrm{~kg}$. The graphite oxidation distribution is decided by the temperature distribution and oxygen distribution in the pebble bed.

Figure 7 shows the distribution of temperature, the graphite oxidation, and the oxygen concentration in the reactor at $144 \mathrm{~h}$. It can be figured out from Figure 7(a) that the maximum temperature appears at the top area in the reactor and the temperature decreased from the top area to the bottom area. The maximum graphite oxidation appears at the bottom reflector and the bottom area of the core. It can be explained from Figure 7(c) that the oxygen is mainly distributed at the bottom area. The air flows into the core from the inner coaxial gas duct and then flows from the bottom reflector, passing through the core, to the top reflector. So the oxygen will be first consumed at the bottom area. The oxygen is consumed up in the bottom part and the temperature range of this part is about $600-800^{\circ} \mathrm{C}$. At this temperature range, the chemical reaction is mainly $\mathrm{C} / \mathrm{O}_{2}$ and $\mathrm{CO}_{2}$ is produced. Figure 7(b) also shows that the graphite 


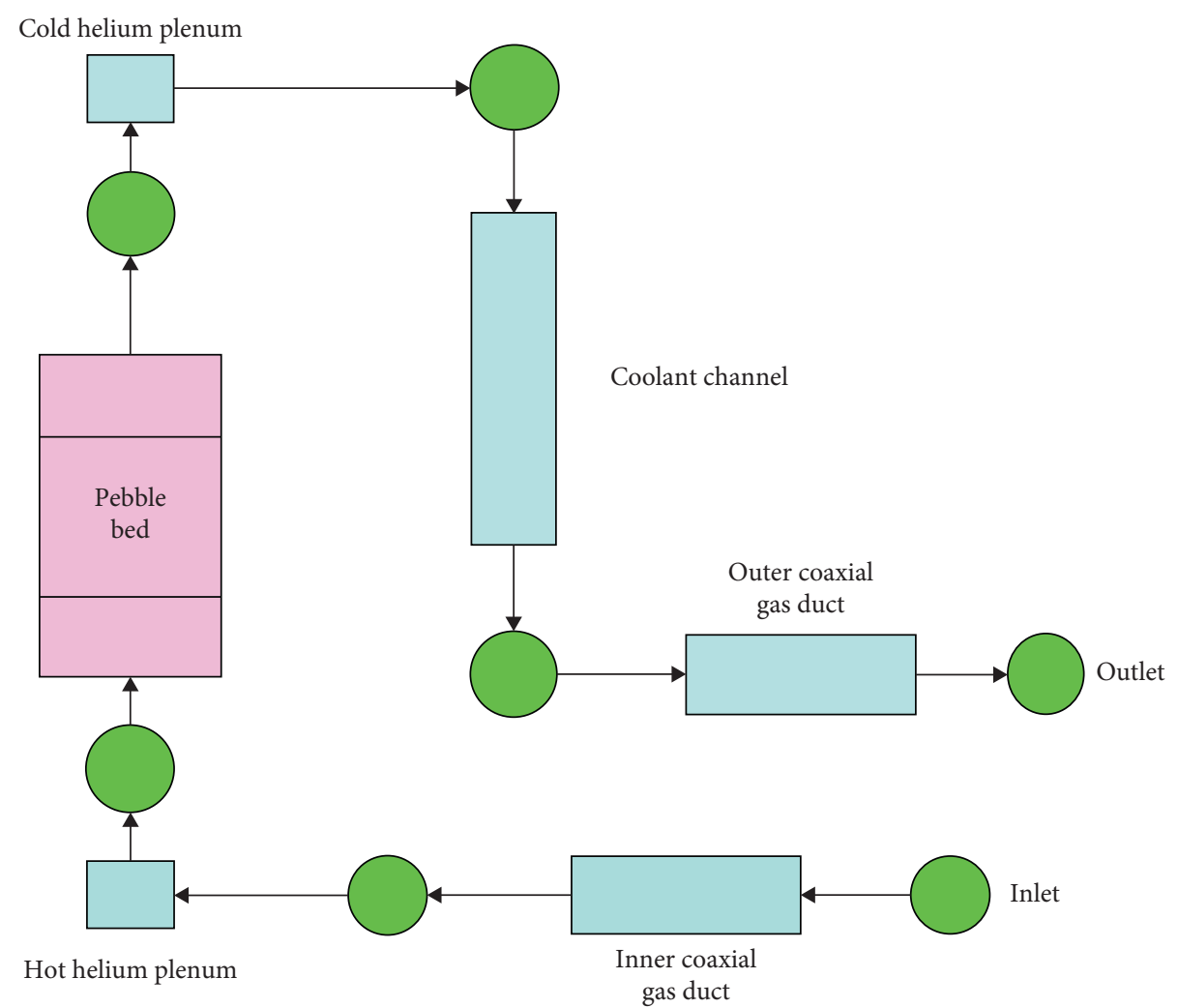

Figure 3: Component connection under the DEGB of the horizontal coaxial gas duct accident.

oxidation is relatively high in the middle area of the core. From Figure 7(a), it can be known that the temperature of this area is about $1000^{\circ} \mathrm{C} . \mathrm{CO}_{2}$ produced by the $\mathrm{C} / \mathrm{O}_{2}$ reaction in the bottom area will react with graphite at $1000^{\circ} \mathrm{C}$ and produced $\mathrm{CO}$. So the graphite oxidation in this region is mainly due to the $\mathrm{C} / \mathrm{CO}_{2}$ reaction.

The diameter of the fuel element of the HTR-PM is $60 \mathrm{~mm}$, and there is a $5 \mathrm{~mm}$ fuel-free zone in outer matrix graphite. The TRISO particles were dispersed in the inner $50 \mathrm{~mm}$ zone of matrix graphite. When the local graphite oxidation reaches $3.75 \times 10^{4} \mathrm{~mol} / \mathrm{m}^{3}$, the outer $5 \mathrm{~mm}$ fuelfree zone of matrix graphite is completely oxidized, and the TRISO fuel particles begin to be exposed. As shown in Figure 7(b), the maximum local graphite oxidation is about $1.67 \times 10^{4} \mathrm{~mol} / \mathrm{m}^{3}$, and $2 \mathrm{~mm}$ of the outer fuel-free zone is oxidized. The TRISO fuel particles will not be exposed.

The maximum local weight loss ratio of the bottom reflector (nuclear graphite IG-110) is about 0.114 . Due to the experiment result by Idaho National Laboratory [7], the weight loss ratio for fracture of IG-110 is 0.647 . So, the integrity of the bottom reflector will not be damaged under this air ingress accident.

These results show that even under the assumption of infinite air in the reactor cavity, the graphite oxidation will not cause unacceptable consequences.

3.3. CO Production. Carbon monoxide produced by the $\mathrm{C} /$ $\mathrm{CO}_{2}$ reaction is flammable gas, and explosion may occur when the $\mathrm{CO}$ concentration and $\mathrm{O}_{2}$ concentration are large enough. As shown in Figure 8, the mole fraction of $\mathrm{CO}$ at the outlet of the horizontal coaxial gas duct is about 0.266 at $144 \mathrm{~h}$. This result assumed that the amount of air which could be diffused into the reactor is infinite, and this assumption is too conservative. Another conservative assumption is that the pressure relief valve of the reactor cavity remains open, and the air concentration in the reactor cavity is only about $5 \%$ [16]. In this condition, the CO mole fraction at the outlet of the horizontal coaxial gas duct is about $2 \%$ [29]. This concentration is small and cannot cause explosion, even though oxygen is enough.

\section{Possible Mitigation Measures}

Many researchers have done much effort on the mitigation measures of the DEGB of the horizontal coaxial gas duct accident for the high-temperature gas-cooled reactor. Since the accident consequences become more serious after the stable natural circulation is established, the onset time of stable natural circulation is very important for the air ingress accident of the high-temperature reactor. Many researchers tried to alleviate the consequence by cutting off the natural circulation or preventing the establishment of natural circulation. The injection of chemical inert gas like helium or nitrogen to prevent the establishment of natural circulation has been proposed. Yan et al. [30] proposed the idea of injecting helium from the top of the core to mitigate the consequence of the double-end of the fuel charging tube 


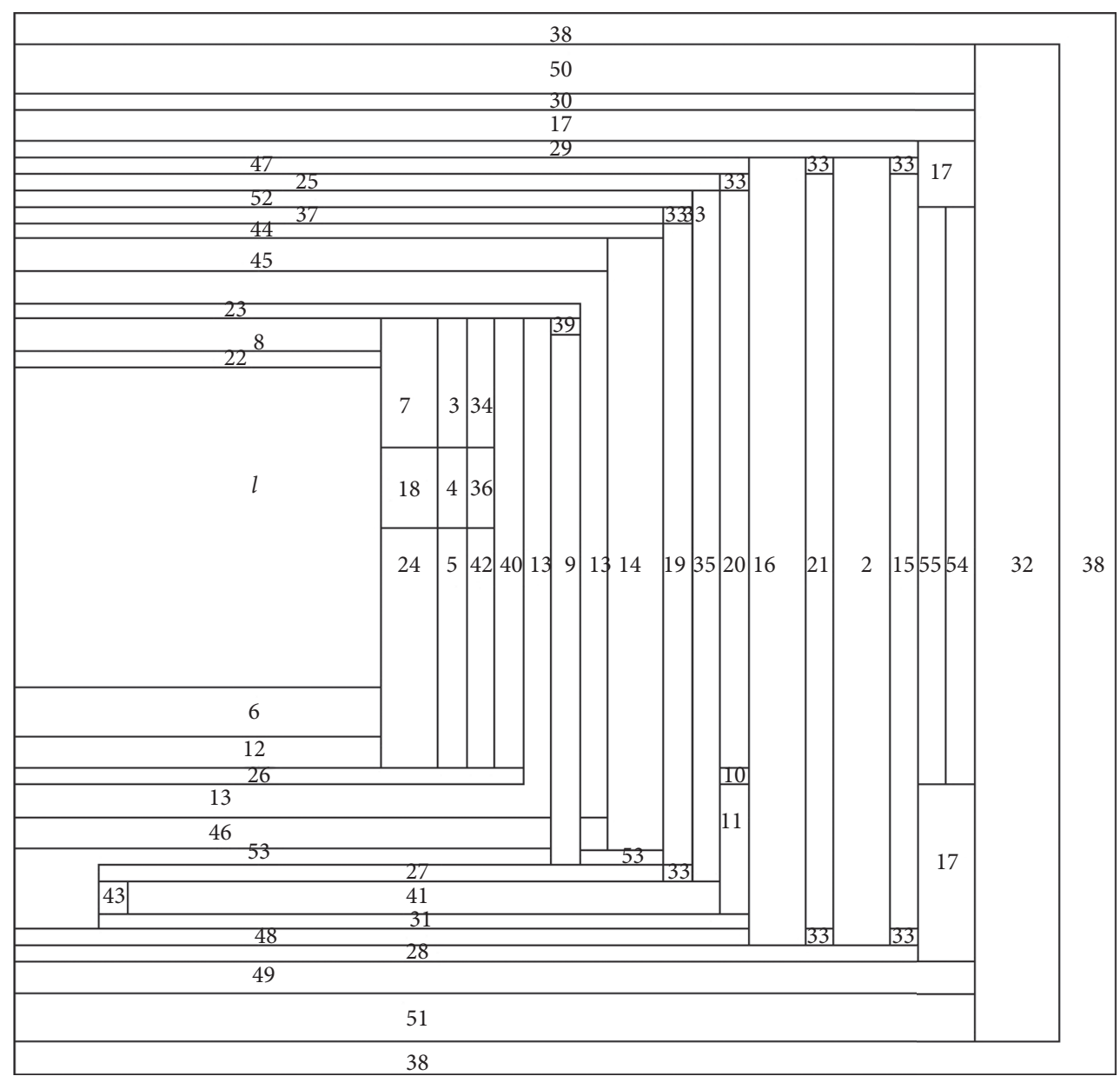

FIGURE 4: TINTE model of the HTR-PM reactor [1]: (1) core; (2) water panel; (3-5) control rod channel; (6 and 12) bottom reflector; (7, 13, $18,24,34,36$, and 42$)$ side reflector; (8) top reflector; (9) coolant channel; $(10$ and 11) core inlet cavity; $(14,45$, and 46$)$ carbon brick; $(15,21$, 28-30, and 54) air gap; (16, 47, and 48) reactor pressure vessel; (17 and 49) thermal insulation; (19, 20, 25, and 37) helium gap; (22) core top cavity; (23) cold helium plenum; (26) hot helium plenum; (27) core bottom cavity; (31) RPV bottom cavity; $(32,50$, and 51) concrete; (35, 41, 44, 52, and 53) core barrel and metal internals; (38) air boundary; (39) throttle; (40) leakage flow; (43) flow passage; (55) metallic plate.

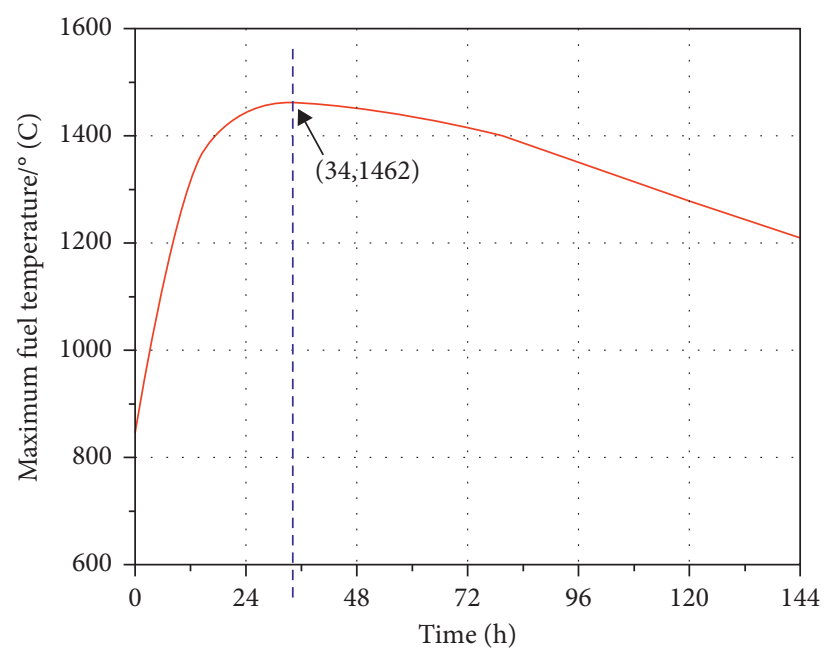

Figure 5: Fuel temperature versus time. 


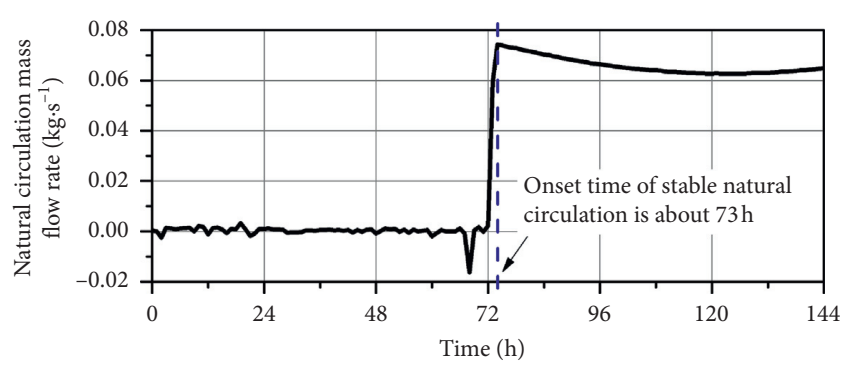

(a)

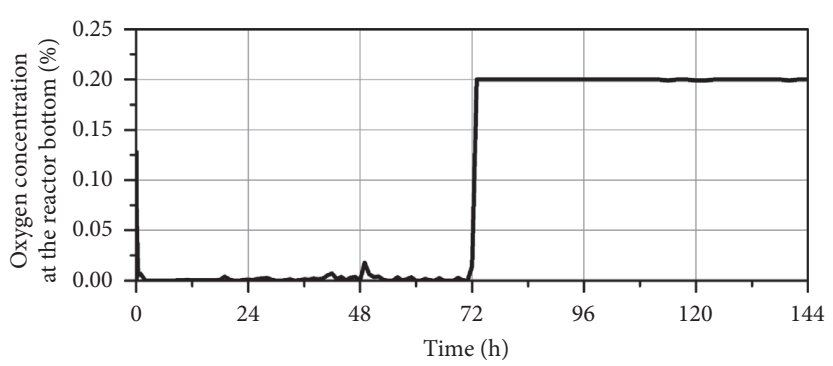

(b)

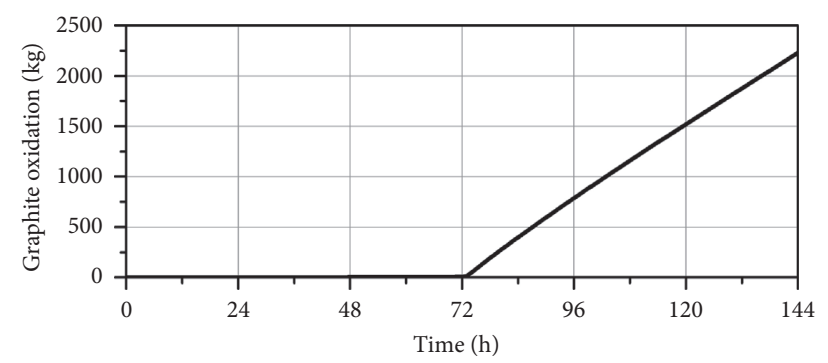

(c)

Figure 6: The natural circulation mass flow rate, the oxygen concentration at the reactor bottom, and the total graphite oxidation versus time.

accident. The simulation results show that the small flow helium from the top of the core was enough to prevent the establishment of natural circulation.

The Idaho National Laboratory [7] also proposed injecting helium to mitigate the consequence for the DEGB of the horizontal coaxial gas duct of GTHTR300 and verified the effectiveness of these mitigation measures by the CFD method. Liu [12] proposed injecting nitrogen from the fuel charging tube to prevent the establishment of natural circulation of the HTR-PM under DEGB of the horizontal coaxial gas duct accident. According to Liu's results, only when the flow rate of nitrogen injection reaches a certain value can the natural circulation be effectively prevented.

4.1. Nitrogen and Helium Injection. Considering the structure of the HTR-PM, injecting chemical inert gas from the fuel charging tube to mitigate the DEGB of horizontal coaxial gas duct accident has been studied by TINTE. The candidate chemical inert gas is helium and nitrogen. Different flow rates of helium $(0.005 \mathrm{~kg} / \mathrm{s}, 0.05 \mathrm{~kg} / \mathrm{s}$, and $0.5 \mathrm{~kg} / \mathrm{s})$ and nitrogen $(1.0 \mathrm{~kg} / \mathrm{s}, 1.5 \mathrm{~kg} / \mathrm{s}$, and $2.0 \mathrm{~kg} / \mathrm{s})$ are injected from the fuel charging tube at $51 \mathrm{~h}$ (before the establishment of natural circulation). The temperature of helium or nitrogen injected is $35^{\circ} \mathrm{C}$. The simulation results by TINTE are shown in Table 1 .

Table 1 shows that the total graphite oxidation with $1.0 \mathrm{~kg} / \mathrm{s}$ nitrogen injected is more than the graphite oxidation without nitrogen injected. That is to say, the consequence is more serious if $1.0 \mathrm{~kg} / \mathrm{s}$ nitrogen is injected from the fuel charging tube. The reason is that the most chemically inert gas injected from the fuel charging tube will flow into the coolant channel through the cold helium plenum at the top of the core according to the structure of the HTR-PM, which can increase the gas density difference between the coolant channel and the core. Therefore, the natural circulation comes into being as soon as the $1.0 \mathrm{~kg} / \mathrm{s}$ nitrogen is injected. So, the total graphite oxidation with $1.0 \mathrm{~kg} / \mathrm{s} \mathrm{ni-}$ trogen injected is more than the total graphite oxidation without injection. The nitrogen injected with a higher flow rate of $1.5 \mathrm{~kg} / \mathrm{s}$ can put off the establishment of stable natural circulation. So, the total graphite oxidation with $1.5 \mathrm{~kg} / \mathrm{s}$ nitrogen injection is less than that without nitrogen injection, while nitrogen injected with $2.0 \mathrm{~kg} / \mathrm{s}$ can overcome the buoyancy force in the reactor core, and even a small fraction of the gas can flow out to the cavity from the inner pipe of horizontal coaxial gas duct. Therefore, the natural circulation can be prevented, and the total graphite oxidation is nearly zero. However, the natural circulation can still be established with the increase of the density difference between the coolant channel and the core. These can also be explained by Figure 9 .

When the mass flow rate of nitrogen injected is $1.0 \mathrm{~kg} / \mathrm{s}$, the natural circulation is established soon and the natural circulation mass flow rate is higher than that without nitrogen injected. That is to say, when the flow rate of nitrogen injected is small, it cannot alleviate the consequences of the air ingress accident and even will make the consequences more serious. When the mass flow rate of nitrogen injected is $1.5 \mathrm{~kg} / \mathrm{s}$ or $2.0 \mathrm{~kg} / \mathrm{s}$, the onset time of natural circulation can be put off and the natural circulation mass flow rate is lower than that without nitrogen injected. This conclusion about the nitrogen injection is in accordance with the conclusion of Liu [12].

For the helium injection in Table 1, no matter the small flow rate $(0.005 \mathrm{~kg} / \mathrm{s})$ or higher flow rate $(0.05 \mathrm{~kg} / \mathrm{s}$ and $0.5 \mathrm{~kg} / \mathrm{s}$ ), the graphite oxidation is quite small. Most of helium injected from the fuel charging tube will flow into the 


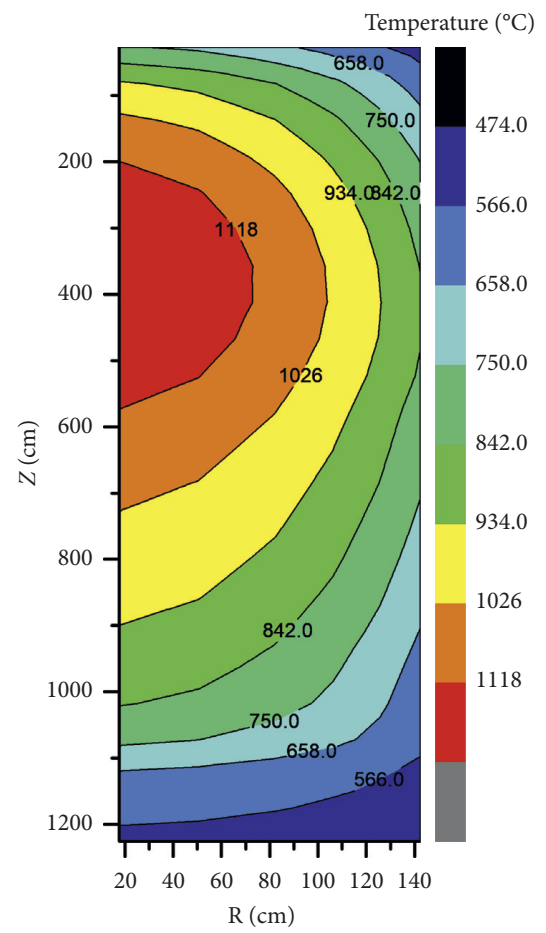

(a)

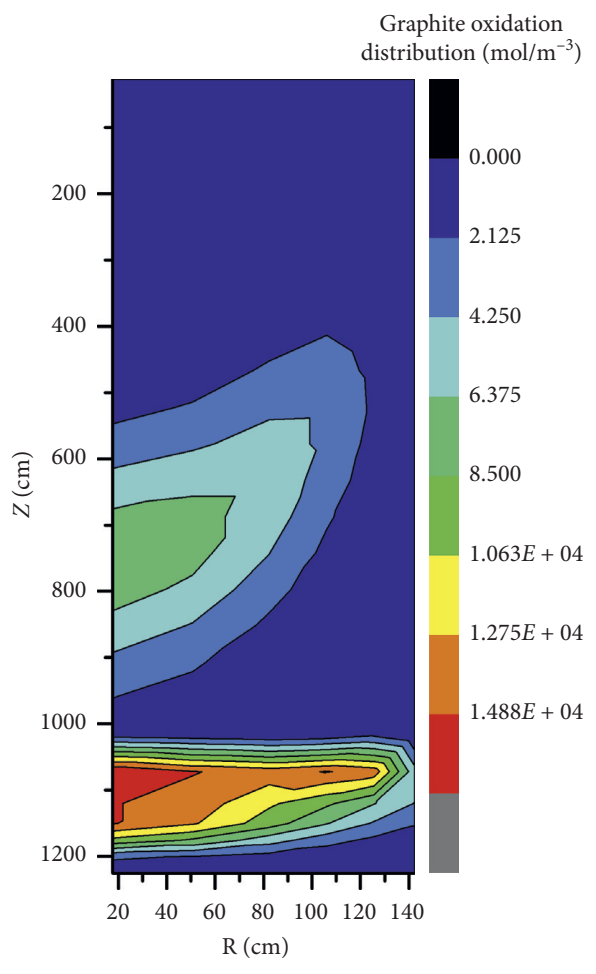

(b)

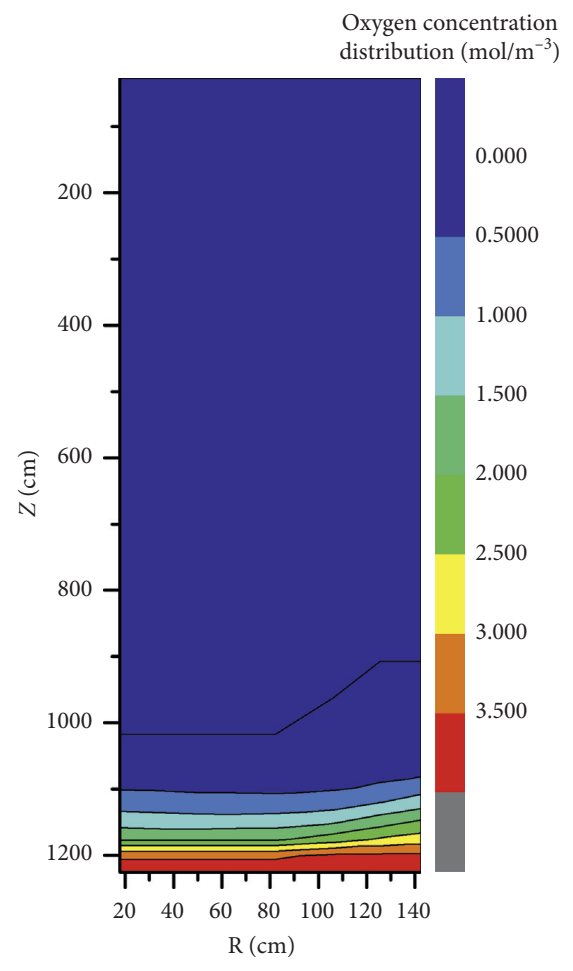

(c)

FIgURE 7: The distribution of temperature, graphite oxidation, and oxygen concentration in the reactor at $144 \mathrm{~h}$.

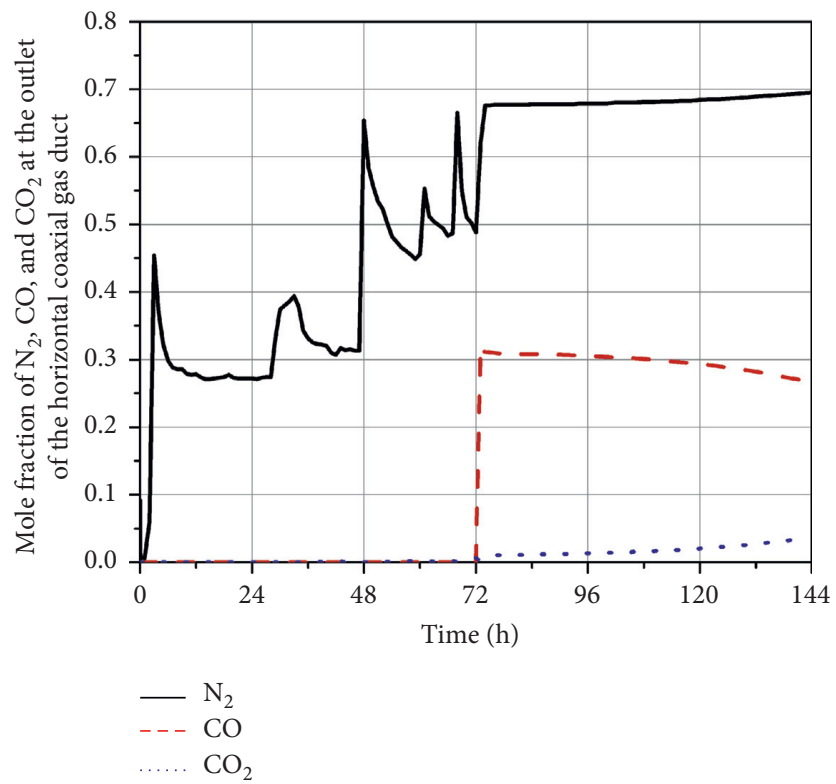

Figure 8: The mole fraction of the gases versus time at the outlet of the horizontal coaxial gas duct.

coolant channel, the molecular weight of helium is very small, and the density difference between the core and the coolant channel will decrease if helium is injected.

The fuel temperature is also an important parameter to evaluate the air ingress accident consequences in addition to the graphite oxidation. When nitrogen is injected, both the maximum fuel temperature and average fuel temperature are lower than those without nitrogen injected. On the one hand, the temperature of nitrogen injected is low; on the other hand, the natural circulation is helpful for heat removal in the pebble bed. So, both the maximum and average fuel temperature are lower than those without nitrogen injection. 
TABLE 1: Simulation results at $144 \mathrm{~h}$ when different flow rates of helium and nitrogen are injected at $51 \mathrm{~h}$.

\begin{tabular}{|c|c|c|c|c|c|c|c|}
\hline & $\begin{array}{l}\text { Without } \\
\text { injection }\end{array}$ & $\begin{array}{c}\mathrm{N}_{2^{-}} \\
1.0 \mathrm{~kg} / \mathrm{s}\end{array}$ & $\begin{array}{c}\mathrm{N}_{2^{-}} \\
1.5 \mathrm{~kg} / \mathrm{s}\end{array}$ & $\begin{array}{c}\mathrm{N}_{2^{-}} \\
2.0 \mathrm{~kg} / \mathrm{s}\end{array}$ & $\begin{array}{c}\mathrm{He}- \\
0.005 \mathrm{~kg} / \mathrm{s}\end{array}$ & $\begin{array}{c}\mathrm{He}- \\
0.05 \mathrm{~kg} / \mathrm{s}\end{array}$ & $\begin{array}{c}\mathrm{He}- \\
0.5 \mathrm{~kg} / \mathrm{s}\end{array}$ \\
\hline Total graphite oxidation $/ \mathrm{mol}$ & 186300 & 228200 & 62380 & 333.3 & 377 & 263.2 & 193.7 \\
\hline $\begin{array}{l}\text { Local maximum graphite oxidation in } \\
\mathrm{core} / \mathrm{mol} \cdot \mathrm{m}^{-3}\end{array}$ & 16760 & 18660 & 18220 & 100 & 187.2 & 138.5 & 98.3 \\
\hline $\mathrm{CO}$ mole fraction at the outlet & 0.265 & 0.009 & 0.0042 & 0 & 0 & 0 & 0 \\
\hline $\mathrm{CO}_{2}$ mole fraction at the outlet & 0.037 & 0.011 & 0.0037 & 0 & 0 & 0 & 0 \\
\hline Maximum fuel temperature $/{ }^{\circ} \mathrm{C}$ & 1210 & 1083 & 1082 & 1108 & 1260 & 1229 & 1110 \\
\hline Average fuel temperature $/{ }^{\circ} \mathrm{C}$ & 870 & 714 & 673 & 622 & 857 & 808 & 629 \\
\hline
\end{tabular}

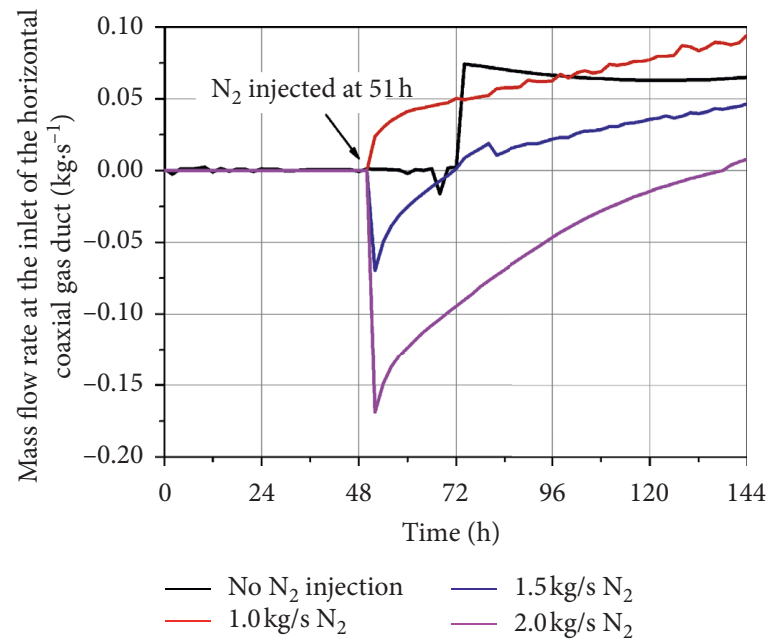

Figure 9: The mass flow rate at the inlet of the horizontal coaxial gas duct at different conditions.

When $0.005 \mathrm{~kg} / \mathrm{s}$ or $0.05 \mathrm{~kg} / \mathrm{s}$ of helium is injected from the fuel charging tube, the natural circulation is not established till $144 \mathrm{~h}$. Because the natural circulation is helpful for heat removal in the pebble bed, the maximum fuel temperature is higher than that without gas injected. Due to the low temperature of helium injected, the average fuel temperature is lower than that without helium injected. While the flow rate of helium injected is $0.5 \mathrm{~kg} / \mathrm{s}$, low-temperature helium can flow to the bottom of the pebble bed. So, the maximum fuel temperature is lower than that without the gas injected.

As to flammable gas $\mathrm{CO}$ produced by reaction $\mathrm{C} / \mathrm{CO}_{2}$, it can be known from Table 1 that chemical inert gas injected from a fuel charging tube could decrease the CO mole fraction at outlet. No matter nitrogen or helium is injected, the $\mathrm{CO}$ mole fraction at the outlet is lower than that without injection, and the explosion probability is decreased.

In conclusion, if nitrogen is injected from the fuel charging tube, only the nitrogen flow rate which reaches some value (such as $2.0 \mathrm{~kg} / \mathrm{s}$ ) can decrease the graphite oxidation, maximum fuel temperature, and $\mathrm{CO}$ mole fraction, namely, alleviating the consequences of this air ingress accident. If helium is injected from the fuel charging tube, no matter small or high flow rate can alleviate the consequences.

4.2. Feasibility Analysis. Considering the structure of the HTR-PM, the nitrogen or helium is injected from the fuel charging tube. The diameter of the fuel charging tube is
$6.5 \mathrm{~cm}$. If the pressure and temperature of nitrogen and helium injected are the same, then the ratio of the velocity of helium and nitrogen in the fuel charging tube is as follows:

$$
\begin{aligned}
\frac{u_{\mathrm{He}}}{u_{N_{2}}} & =\frac{G_{\mathrm{in}, \mathrm{He}} /\left(\mathrm{PM}_{\mathrm{He}} / \mathrm{RT} \times A_{\mathrm{in}}\right)}{G_{\mathrm{in}, N_{2}} / \mathrm{PM}_{N_{2}} / \mathrm{RT} \times A_{\mathrm{in}}} \\
& =\frac{G_{\mathrm{in}, \mathrm{He}}}{G_{\mathrm{in}, N_{2}}} \times \frac{M_{N_{2}}}{M_{\mathrm{He}}} .
\end{aligned}
$$

$G_{\text {in,He }}$ is the mass flow rate of helium injected and suppose it takes $0.005 \mathrm{~kg} / \mathrm{s}$. $G_{\mathrm{in}, \mathrm{N} 2}$ is the mass flow rate of nitrogen injected and suppose it takes $1.5 \mathrm{~kg} / \mathrm{s} . M_{\mathrm{He}}$ and $M_{\mathrm{N} 2}$ are the molar mass of helium and nitrogen, respectively. Therefore, it can be known that $u_{\mathrm{He}} / u_{N_{2}}$ is about 0.02 . The high speed will affect the mechanical properties of the fuel charging tube. For this reason, helium is more suitable for the mitigation measure. Further, considering the total mass of the nitrogen or helium, one day will need $129600 \mathrm{~kg}$ nitrogen or $432 \mathrm{~kg}$ helium. It means thousands of bottles of nitrogen or hundreds of bottles of helium. It is difficult for the reactor plant to restore so many bottles. Helium is more suitable if it is urgently transported from another place.

As mentioned above, helium injected at $51 \mathrm{~h}$ (before natural circulation established) can effectively prevent the establishment of natural circulation. Figure 10 shows the results if helium is injected after the establishment of natural circulation. It can be figured out that when $0.005 \mathrm{~kg} / \mathrm{s}$ helium 


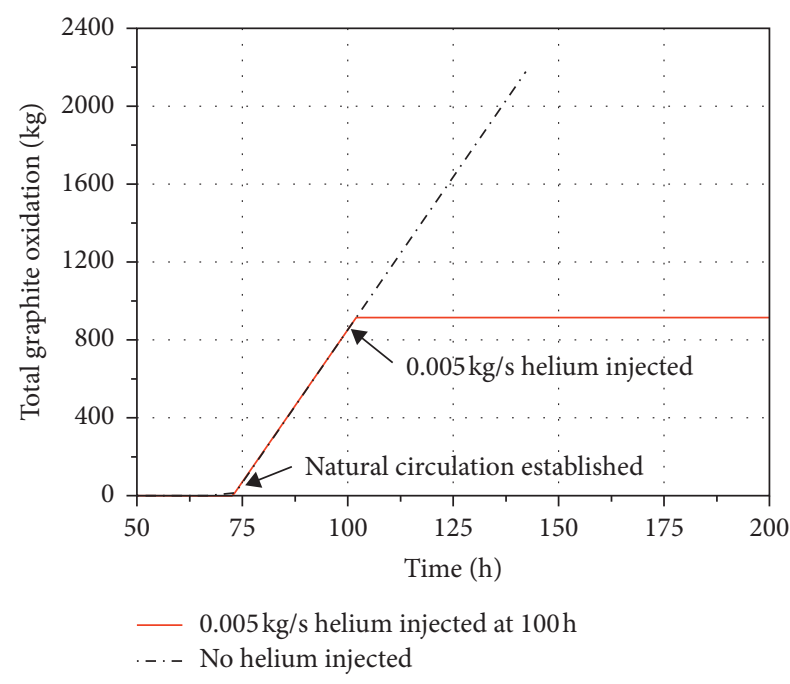

Figure 10: Total graphite oxidation at different conditions.

is injected at $100 \mathrm{~h}$, the total graphite oxidation stops increasing immediately. The natural circulation is cut off as soon as helium is injected from the fuel charging tube. The graphite in the reactor is almost no longer oxidized when the natural circulation is cut off. Therefore, even if the natural circulation is established, the helium injection still can mitigate the consequences effectively.

\section{Conclusions}

The double-ended guillotine break (DEGB) of the horizontal coaxial gas duct accident of the HTR-PM and its mitigation measures have been analyzed by TINTE in this work. The maximum fuel temperature of this air ingress accident is about $1462^{\circ} \mathrm{C}$, which is lower than the fuel temperature design limitation. The SiC layer of the coated fuel particles would not be damaged under this accident. The onset time of stable natural circulation is about $73 \mathrm{~h}$ under some conservative assumptions. Graphite in the reactor would be oxidized significantly after the stable natural circulation is established. The total amount of graphite oxidation in the reactor is about $2231 \mathrm{~kg}$ till $144 \mathrm{~h}$.

Considering the structure of the HTR-PM, helium or nitrogen injected from the fuel charging tube has been used as the mitigation measures. When different flow rates of helium $(0.005 \mathrm{~kg} / \mathrm{s}, 0.05 \mathrm{~kg} / \mathrm{s}$, and $0.5 \mathrm{~kg} / \mathrm{s})$ and nitrogen $(1.0 \mathrm{~kg} / \mathrm{s}, 1.5 \mathrm{~kg} / \mathrm{s}$, and $2.0 \mathrm{~kg} / \mathrm{s})$ are injected into the reactor, the simulation results show that helium and nitrogen have different performances. For nitrogen, only the higher flow rate $(1.5 \mathrm{~kg} / \mathrm{s}$ or $2.0 \mathrm{~kg} / \mathrm{s})$ could mitigate the consequences of this air ingress accident. For helium, even a small flow rate $(0.005 \mathrm{~kg} / \mathrm{s})$ could prevent the establishment of natural circulation and mitigate the consequences.

Feasibility analyses show that the velocity and usage amount are too much for nitrogen. There may be some difficulties in the actual operation process. Further analysis figured out that $0.005 \mathrm{~kg} / \mathrm{s}$ helium injected could also cut off the natural circulation even though it has been established. Considering these advantages, helium injected with a small flow rate from the fuel charging tube has been suggested as the mitigation measures for the DEGB of the horizontal coaxial gas duct accident.

The more detailed performances of nitrogen injection and helium injection will be studied in the future.

\section{Data Availability}

The data used to support the findings of this study, for example, the data used to build the model of HTR-PM, have not been available because theses belong to engineering design parameters and could not be made available at present.

\section{Conflicts of Interest}

The authors declare that they have no conflicts of interest.

\section{Acknowledgments}

This work was supported by the National Key R\&D Program of China (Grant no. 2018YFB1900501) and the National S\&T Major Project (Grant no. ZX069).

\section{References}

[1] Y. Zheng and L. Shi, Y. J. Dong, Thermohydraulic transient studies of the Chinese 200MWe HTR-PM for loss of forced cooling accidents," Annals of Nuclear Energy, vol. 36, no. 6, pp. 742-751, 2009.

[2] G. H. Lohnert and H. Reutler, "The modular HTR-a new design of high-temperature pebble-bed reactor," Nuclear Energy, vol. 22, no. 3, pp. 197-201, 1982.

[3] Y. H. Zheng and L. Shi, "Air ingress analysis for two primary loop pipes rupture of HTR-PM," Atomic Energy Science and Technology, vol. 44, no. 1, pp. 253-257, 2010.

[4] N. Kohtz, Thermal Hydraulic and Oxidation Phenomena during Air Ingress Accidents in Pebble and Block Type HTRR. Eurocourse on Safety, Materials and Components, Cadarache, Saint-Paul-lez-Durance, France, 2008.

[5] M. Hishida and T. Takeda, "Study on air ingress during an early stage of a primary-pipe rupture accident of a hightemperature gas-cooled reactor," Nuclear Engineering and Design, vol. 126, no. 2, pp. 175-187, 1991.

[6] M. Hishida, M. Fumizawa, T. Takeda, M. Ogawa, and S. Takenaka, "Researches on air ingress accidents of the HTTR," Nuclear Engineering and Design, vol. 144, no. 2, pp. 317-325, 1993.

[7] C. H. Oh, E. S. Kim, H. C. No et al., Final Report on Experimental Validation of Stratified Flow Phenomena, Graphite Oxidation, and Mitigation Strategies of Air Ingress Accidents, Idaho National Laboratory (INL), Idaho Falls, ID, USA, 2011.

[8] H. S. Lim and H. C. No, "GAMMA multidimensional multicomponent mixture analysis to predict air ingress phenomena in an HTGR," Nuclear Science and Engineering, vol. 152, no. 1, pp. 87-97, 2006.

[9] T. Shiga, Y. Tanaka, and T. Takada, "Process of air ingress during a depressurization accident of GTHTR300," Science and Technology of Nuclear Installations, Science and Technology of Nuclear Installations, vol. 2018, 15 pages, 2018.

[10] B. T. Liu, Study on air ingress accident of $10 \mathrm{MW}$ high temperature gas-cooled test reactor, Ph.D. Thesis, Tsinghua University, Beijing, China, 1998. 
[11] Y. H. Zheng, F. B. Chen, and L. Shi, "Analysis of diffusion process and influence factors in the air ingress accident of the HTR-PM," Nuclear Engineering and Design, vol. 271, pp. 397-403, 2014.

[12] P. Liu, Y. Chen, J. Sun et al., "Study on air ingress of the 200 MWe pebble-bed modular high temperature gas-cooled reactor," Annals of Nuclear Energy, vol. 98, pp. 120-131, 2016.

[13] W. Xu, Y. H. Zheng, L. Shi, and P. Liu, "Oxidation analyses of massive air ingress accident of HTR-PM," Science and Technology of Nuclear Installations, vol. 20169 pages, 2016.

[14] W. Xu, Y. H. Zheng, and L. Shi, "The influence of nuclear graphite oxidation on air ingress accident of HTR-PM," Annals of Nuclear Energy, vol. 110, pp. 1242-1248, 2016.

[15] C. Wang, "Study on water and air ingress accident in the high temperature gas -cooled test reactor HTR-10," Master. Thesis, Tsinghua University, Beijing, China, 1994.

[16] P. Liu, Research on air ingress accident and its key features analysis of HTR-PM, PhD. Thesis, Tsinghua University, Beijing, China, 2016.

[17] A. Lauer and W. Scherer, The Reactor Dynamics Program TINTE: Introduction and Overview, Institut für Sicherheitsforschung und Reaktortechnik (ISR), Dublin, OH, USA, PreJuSER-35324, 2003.

[18] H. Zhang, J. Guo, J. Lu, F. Li, Y. Xu, and T. J. Downar, “The improvement of coupling method in TINTE by fully implicit scheme," Nuclear Science and Engineering, vol. 190, no. 2, pp. 156-175, 2018.

[19] H. Zhang, J. Guo, J. Lu, F. Li, Y. Xu, and T. J. Downar, “An assessment of coupling algorithms in HTR simulator TINTE," Nuclear Science and Engineering, vol. 190, no. 3, pp. 287-309, 2018.

[20] W. Scherer, H. Gerwin, T. Kindt et al., "Analysis of reactivity and temperature transient experiments at the AVR hightemperature reactor," Nuclear Science and Engineering: The Journal of the American Nuclear Society, vol. 97, no. 1, p. 1, 1987.

[21] Y. L. Sun, X. Sun, and Y. Zheng, "Voruntersuchungen zum experiment NACOK mit dem reaktordynamik-programm TINTE," KFA-ISR-IB-, 14/93, vol. 97, 1993.

[22] Y. Zheng and M. M. Stempniewicz, "Investigation of NACOK air ingress experiment using different system analysis codes," Nuclear Engineering and Design, vol. 251, pp. 423-432, 2012.

[23] Y. Zheng, M. M. Stempniewicz, Z. Chen, and L. Shi, "Study on the DLOFC and PLOFC accidents of the 200 MWe pebble-bed modular high temperature gas-cooled reactor with TINTE and SPECTRA codes," Annals of Nuclear Energy, vol. 120, pp. 763-777, 2018.

[24] H. Gerwin and W. Scherer, "Zur Validierung des Reaktor dynamik programm systems TINTE: graphit-Korrosion mit Luft, Vergleichsrechnungen zum Experiment VELUNA R," Institut für Sicherheitsforschung und Reaktortechnik (ISR), KFA-ISR-IB-8/92, 1992.

[25] X. Y. Yun, Y. H. Zheng, X. Q. Jing et al., "Uncertainty analysis on decay heat of pebble-bed high temperature gas-cooled reactor," Atomic Energy Science and Technology, vol. 47, no. 7, pp. 1121-1126, 2013.

[26] H. Chen, L. Fu, G. Jiong, S. Ximing, and W. Lidong, "Quantitative analysis of uncertainty from pebble flow in HTR," Nuclear Engineering and Design, vol. 295, pp. 338-345, 2015.

[27] J. Guo, F. Li, L. D. Wang et al., "Progress in uncertainty analysis for high-temperature gas-cooled reactor," Atomic Energy Science and Technology, vol. 53, no. 7, pp. 1221-1229, 2019.
[28] C. Hao, P. J. Li, D. She et al., "Sensitivity and uncertainty analysis of the maximum fuel temperature under accident condition of HTR-PM," Science and Technology of Nuclear Installations, vol. 202021 pages, 2020.

[29] W. Xu, Y. L. Li, and L. Shi, "Oxidation analysis of the air ingress accident for HTR-PM," Nuclear Science and Engineering, vol. 39, no. 02, pp. 104-111, 2019.

[30] X. L. Yan, T. Takeda, T. Nishihara, K. Ohashi, K. Kunitomi, and N. Tsuji, "A study of air ingress and its prevention in HTGR,” Nuclear Technology, vol. 163, no. 3, pp. 401-415, 2008. 